2) Z. Holzbecher, P. Púlkráb : Collection Czech. Chem. Commun., 27, 1142 (1962).

3) Z. Holzbecher : Microchem. J., 9, 288 (1965).

4) Z. Holzbecher : Acta Chim. Hung. Tomus, 27, 413 (1961).

5) Z. Holzbecher : Collection Czech. Chəm. Commun., 26, 1204 (1961).

6) 行野豊三，行口宽一：本誌，20，997（1971）。

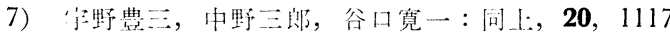
(1971).

Fluorometric determination of aluminum. (Studies on the hydrazone derivatives in fluorometric analysis. II.) Toyozo Uno* and Hirokazu TANIGUCHI** (* Faculty of Pharmaceutical Sciences, Kyoto University, Sakyo-ku, Kyoto-shi; **Meiji College of Pharmacy, Setagaya-ku, Tokyo)

Four derivatives of 2-hydroxy-1-naphthaldehyde hydrazones (from acetic acid hydrazide, phenylacetic acid hydrazide, benzoic acid hydrazide and isonicotinic acid hydrazide) were synthesized.

The spot test on the fluorescence due to the reac. tions between these hydrazons and various metal ions indicated that they were useful for the analysis of aluminum. 2-Hydroxy-1-naphthaldehyde benzoic acid hydrazone $(\mathrm{HNBH})$ gave the strongest fluores cence and a fluorometric method for the determination of aluminum was established by using HNBH. The recommended procedure was as follows. To a sample solution of $4 \mathrm{~m} l$ were added $1 \mathrm{~m} l$ of acetate buffer solution $(\mathrm{pH} 4.6), 6 \mathrm{ml}$ of mixed solvent $\left(\mathrm{CH}_{3} \mathrm{OH}\right.$ : $\mathrm{DMF}=2: 1$ ) and $2 \mathrm{ml}$ of $0.004 \% \mathrm{HNBH}$ in ethanol. The solution was then warmed at $40 \sim 42^{\circ} \mathrm{C}$ and was diluted to $20 \mathrm{ml}$ with $50 \%$ methanol. Blue fluores. cence with the maximum at $475 \mathrm{~m} / \mu$ was measured. From 0.1 to $1.0 \mu \mathrm{g}$ of aluminum per $\mathrm{m} l$ was success. fully determined.

(Received Mar. 1, 1971)

\title{
入射角度大の赤外全反射吸収スペクトル法による 高分子測定の研究
}

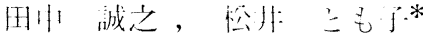 \\ (1971 作 2 月 15 П受理)
}

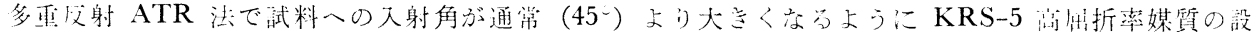

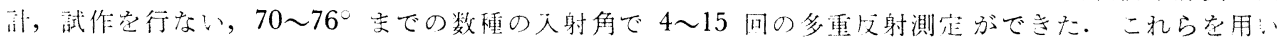

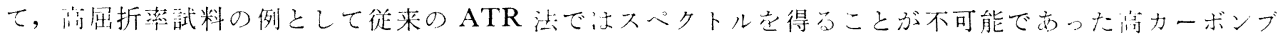

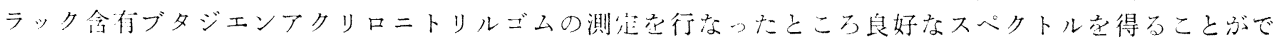

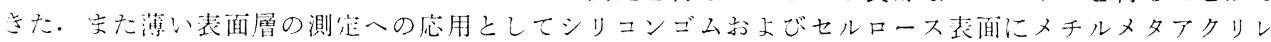
ートをコーティングした試料の測定芯行なったところ，45⼊射で注第 2 層のピークのたる不明りょう

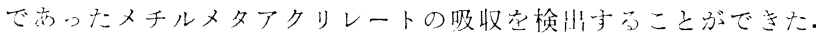

$$
1 \text { 緒 }
$$

高分子化合物の赤外吸収スペクトルを測定当る埸合， 往来の透過法では寺べての物質が測定できる上はかきら

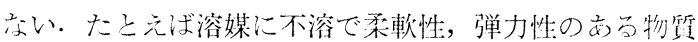
ふどは微粉末にするこ上もできず，スペクトルを得るこ よは相難であるし，をた早い膜あるいは板の形でしふ得 られないもの，さらに不透明な物の上に塗られて調製さ

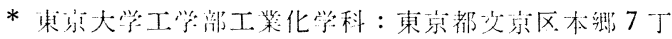

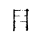

れた薄い脱などはその文の形では測定不能ですっ。こ

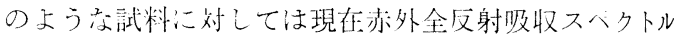
法（以下ATR 汒上略記）が適用され，この種の䦓題の 多くのものが解汱されている。

これらの測定条件としては一般に入射何 45 で1 ない

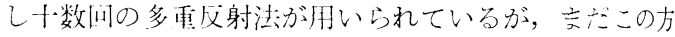

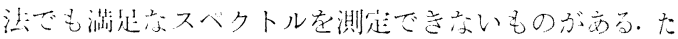

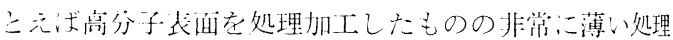

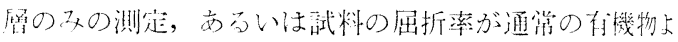

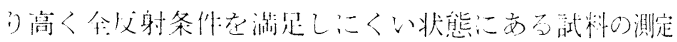


就場合がそれであり，これら忌取り报う绦こは倠来

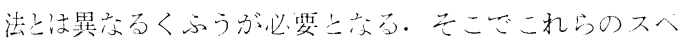

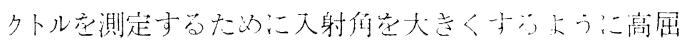

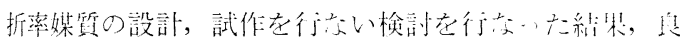

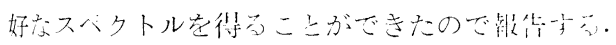

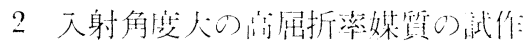

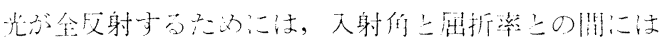

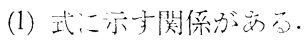

$n_{2}<n_{1} \sin \theta$

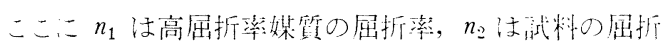

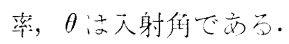

安たATR スベクトルでは全反射面に新いて武料八の

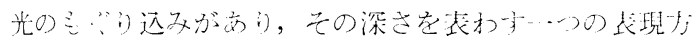

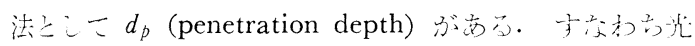

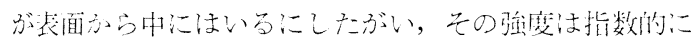

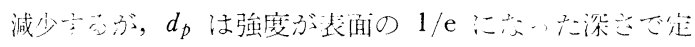

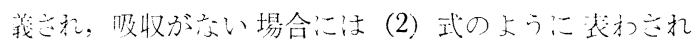
る1).

$$
d_{p}=-\frac{\lambda_{1}}{2 \pi\left(\sin ^{2} \theta-n_{21^{2}}\right)^{12}}
$$

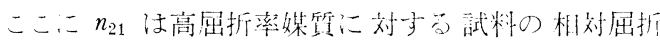

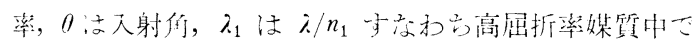

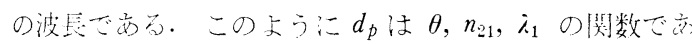

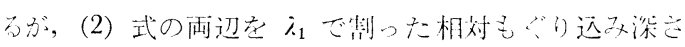

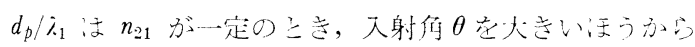

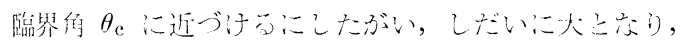

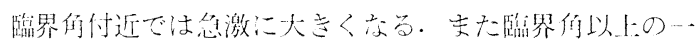
定の天射们に対しては $n_{21}$ が小になる添よ゙ $d_{p} / \lambda_{1}$ は小上

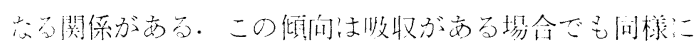
考えてよい2).

高屈折率媒留之乙て一般に利用されている KRS-5 文

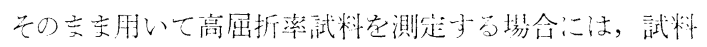
の屈折率が KRS-5のそれ在こえないかきり，(1) 式の

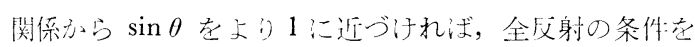

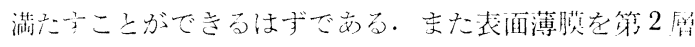

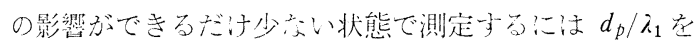

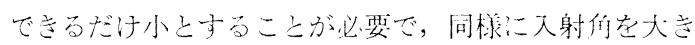
く与ることより测定が可能と思われる。床寺， $d_{p} / \lambda_{1}$ が減少子ると必然的にピークが小さく忞るので，これら の測定には多重反射法を朋いるここが必要である。

したがって住来のナ法より大きい入射们で入射させ るために，KRS-5 の入射面の北きを変兑，炕が空父上
KRS-5 上の界面で屈折することにより试料入の入射何 が変化することを利用して高属折率媒質の設部試作を行 沈た。亦扮，これらの試作品は日本分光工業に依頼し 作製した。

Fig. 1 に䛧用した各種の KRS-5 フリズムの形をふ

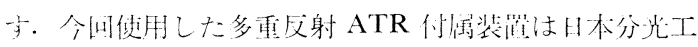
棠製 ATR-6 型（Fig.2，a）で㐫り，Fig.2，b，cに亦 与上う汇第 2 ミラーが約 15 程度回䡆可能であるので, この可転估置を選択することにより，Fig. 1 に少与よう

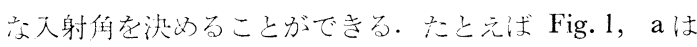
通漟の多重反射用高屈折率媒質で，その入射面は $45^{\circ}$ に 力 $\cdots$ ト亡れて抢り， $\varphi=45^{\circ}$ で試料への入射们 $\theta$ は $45^{\circ}$

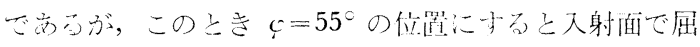
折し， $\theta$ は $49^{\circ}$ となる。亦た試作品bでは同じく入射面 だ光が屈折し， $\varphi=45^{\circ}$ の上き $\theta$ は $70^{\circ}, \varsigma=55^{\circ}$ のとき $\theta$ は $73^{\circ}$ となる. 以下同栐であるが， dでは にすると入射面に光がはいら尔いた测定不能となる。 このように種々の形の高屈折率媒般製作し，第 2 ミラ 一の们度上合わせて推来のもの上りはるか汇大きな入射 侍の巽択を行なえるようにし，スペクトル測定老行なっ

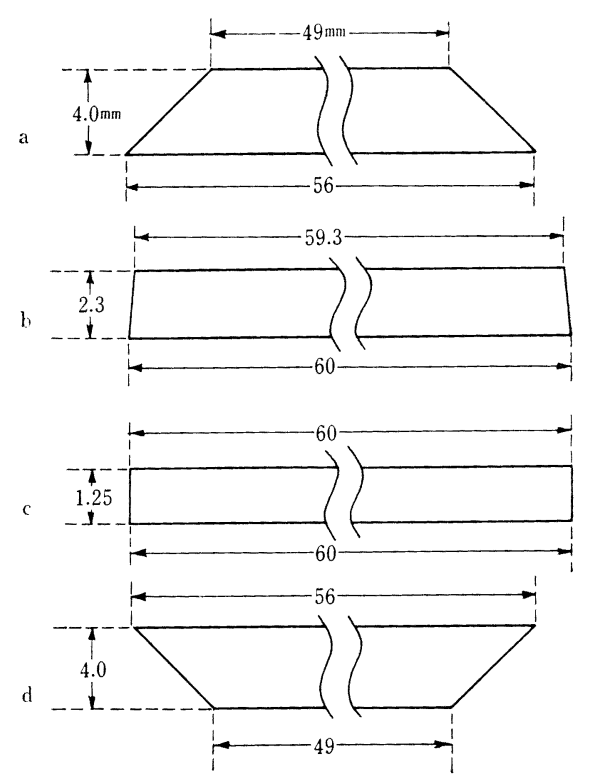

Fig. 1 Various types of prisms and incidence angles for two kinds of $\mathrm{c}^{+}$(† See Fig. 2)

$\begin{array}{lcccc} & \text { a } & \text { b } & \text { c } & \text { d } \\ \theta\left(\varphi=45^{\circ}\right) & 45^{\circ} & 70^{\circ} & 72^{\circ} & \text { Not applicable } \\ \theta\left(\varphi=55^{\circ}\right) & 49^{\circ} & 73^{\circ} & 76^{\circ} & 69^{\circ} \\ \begin{array}{c}\text { Number of } \\ \text { reflection } \\ \left(\text { at } \varphi=45^{\circ}\right)\end{array} & 13 & 7 & 15 & -\end{array}$



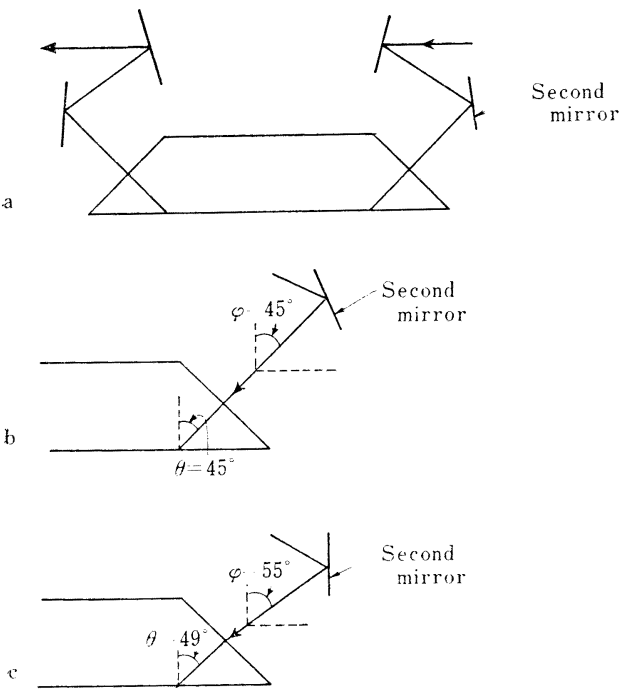

Fig. 2 Optical systems of the ATR attachment

䠞。

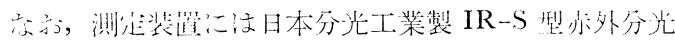

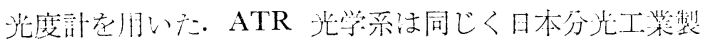
のもので，前紀のもの以外に比較のた放，1 回反射型 (ATR-1 型全反射測定装置: 入射何 30 60 可恋,

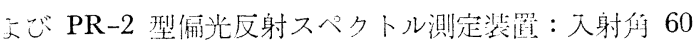
〜 $80^{\circ}$ 可変）装置も使用した。

\section{3 人射角度大比設定した KRS-5} プリズムによる測定結果

\section{1 プリズムのブランクおよび性能の比較}

Fig. 1，dのプリズムのみのブランクを測定したをこ 万 Fig. 3，(1) d 江示寺上うに，全領域約 30\% の透過 光が得られた。 その他のものについても最もエネルギー の少ないもの（Fig. 1， c ）でも 15\% 程度の唀過光が方 り，補償側をある程度減光することによりスペクトル测

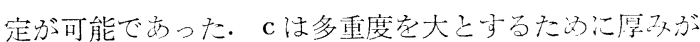
非常に薄く，光学系を合わせることがやや困難である が，このものを 2 枚重衫て便用することにより，利用工 ネルギーが増加し満足すべきスペクトル测定ができた。

この際 2 枚のプりズムの間にも試料面がプリズム面に揬 与るように試料在そう入する必要がある。しかしc 沈を

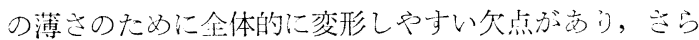
亿製作上の問題，媒質がよごれた場合の再研摩などを考 虑すると，かなりな多重度を必要としないかぎりる はd在使用するほうがよりよい上うに思われた。

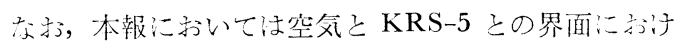

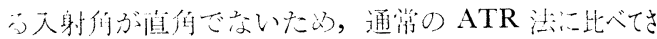

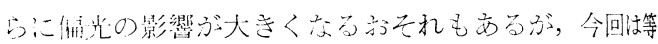

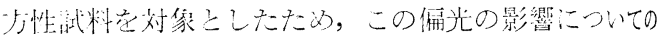

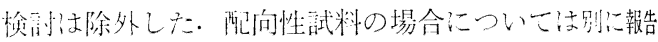
-5ㄱ․

\section{2 高屈折率高分子試料への応用}

高出折率就料上してカーボンブラック入りブタジエン アクリロニトリルゴム（以下 NBR 上略記）取り上计，

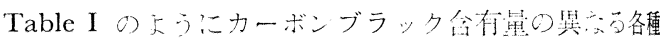

Table I The ratio of main components in rubber sample

\begin{tabular}{cc} 
Sample no. & Carbon black/Butadiene acrylonitrile \\
\hline$(1)$ & $0 / 100$ \\
$(2)$ & $10 / 100$ \\
$(3)$ & $20 / 100$ \\
$(4)$ & $40 / 100$ \\
\hline
\end{tabular}

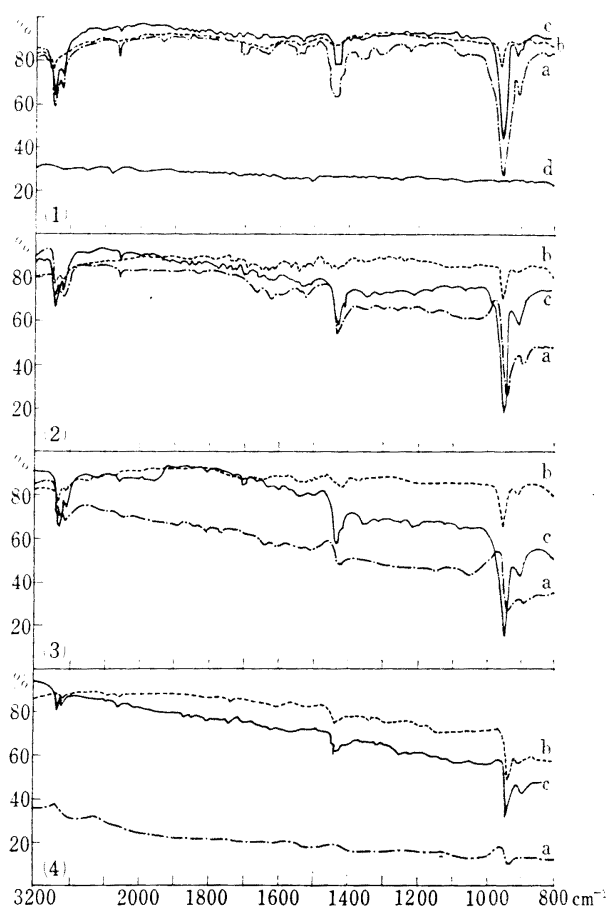

Fig. 3 ATR spectra of butadiene acrylonitrile rubber containing carbon black

(1) Sample 1†, (2) Sample 2†, (3) Sample 3†, (t) Sample $4 \dagger(\dagger$ See Table I) $\{(1) \sim(3)$ four reflec. tions, (4) two reflections\}; a - $\theta: 45^{\circ}$, one reflection; b - - $\theta: 70^{\circ}$, one reflection; $\mathrm{c}-$ $\theta: 70^{\circ}$, multiple reflection; $\mathrm{d} \longrightarrow$ prism blank (no attenuater in reference beam) 


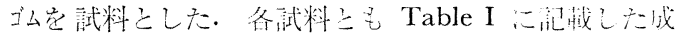

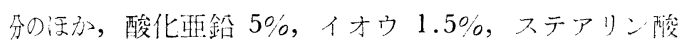
$10 \%$ ，加硫促進剂 $1 \%$ 定含有している.

これらの試料在入射危 $45^{\circ} ， 70^{\circ}$ 冬1间反射法晾区ご

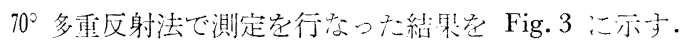

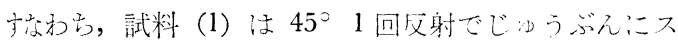
ヘクトル測定が可能で少かが F Fig. 3, (1)a\}，力ーボン ブラックの含有量が增加与るにしたがいピークがくがれ

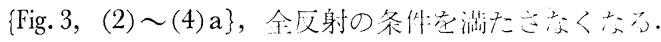

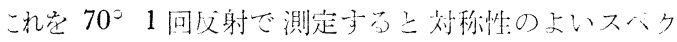

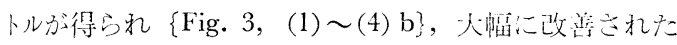
が，一般にピークの強废が小さく法のたので 4 回あるい

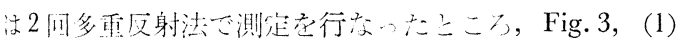

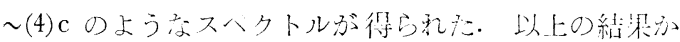
ら今立で测定困難上されていたカーボンブラックが多星

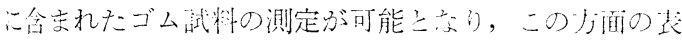

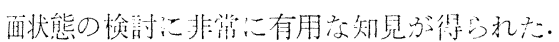

\section{3 表面薄膜コーティング層測定への応用}

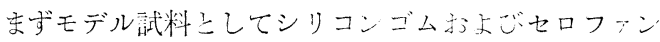
表面にポリメチルメタクリレート（以下 MMA 之畍北） 艺コーティングした試料について梌討在行衣った・歺小 わち約 $10 \mathrm{~cm}^{2}$ のシリコンゴム立たはセロファンに一定

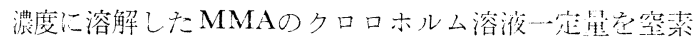

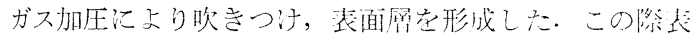

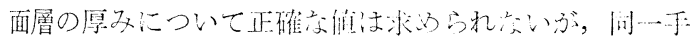

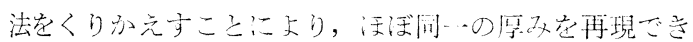

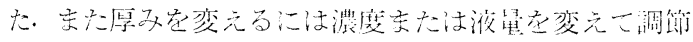
したＦig. 4 にシリコンゴム方よびャロフォン表面に

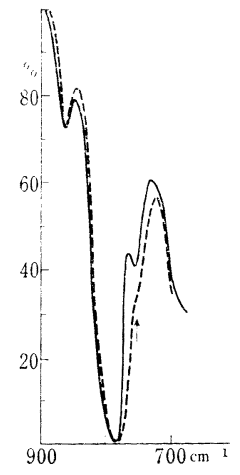

(1) On silicon rubber

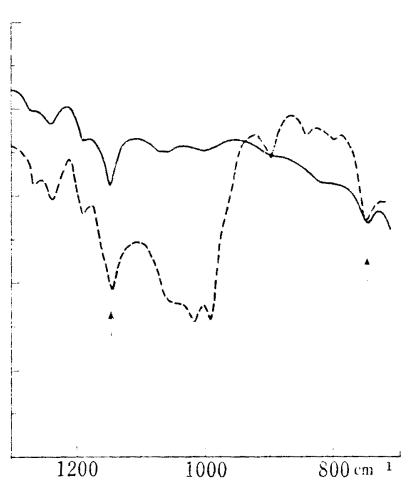

(2) On cellulose
Fig. 4 ATR spectra of methyl methacrylate coating

- $\theta: 72^{\circ}, 15$ reflections; $\ldots-\theta: 45^{\circ} 3$ reflections; $\longrightarrow$ Nethyl methacrylate band
MMA 約 3 艺コーティングした試料のスハクトル基

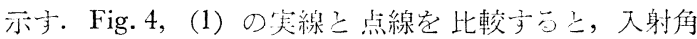
$72^{\circ}$ で測定一る上 45 大射ではシリコンゴムのピークに 妨害されて不明りょうであった MMAの750 $\mathrm{cm}^{-1}$ の ピーク在明りょうに梌将することができ志。たセロフ

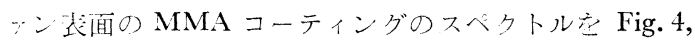

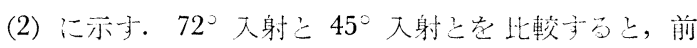
者ではセロフッンのピークが活上えビ法くり，MMA のビークが主上六ったこのように 72 入射法では表面 層の吸收を第 2 層の吸收の妨害老少心くした状態で測定 することがだきる。

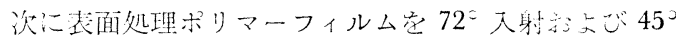

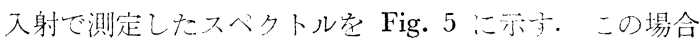
$1300 \sim 1400 \mathrm{~cm}^{-1}$ 領域に実線上点線とごヒーク咍度比の

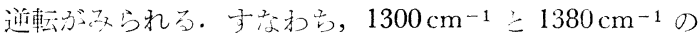
2 杖のビークは心つの入射角で強度比が異ふり，45 入 射では $1380 \mathrm{~cm}^{-1}$ のビークの注うが強ふッけのに反し， $72^{\circ}$ 入射では $1380 \mathrm{~cm}^{-1}$ ぶ相対的に減少己， $1300 \mathrm{~cm}^{-1}$

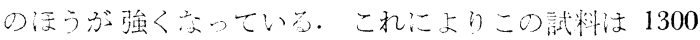

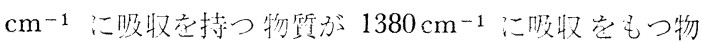
質の表面に加工されているものと推定字ること出でき る。この結果から明らかなよう，前 2 例と異なり，表 面層と第 2 層の特性吸收が重複していても 2 種の入射角 た ATR スヘタトルを測定し，その相対的ンスヘクトル

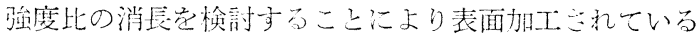

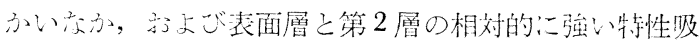
牧位䍜の推公汸ごにも有用であった。

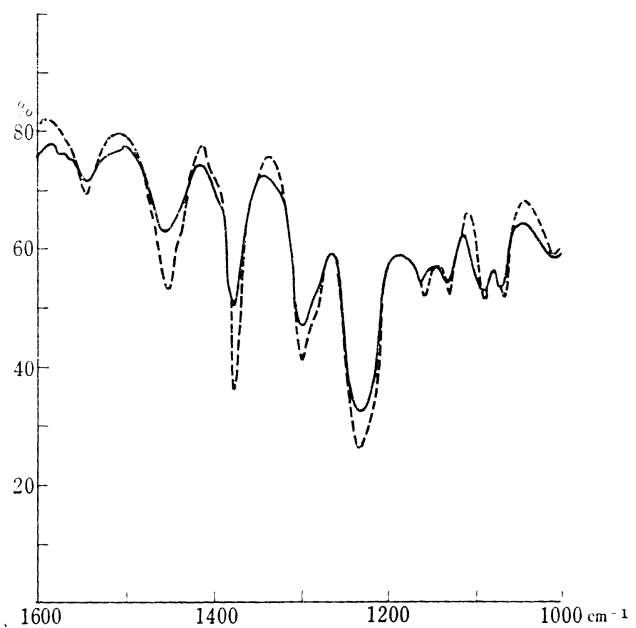

Fig. 5 ATR spectra of a coating polymer - $\theta: 72^{\circ}, 15$ reflections; $\ldots . \theta: 45^{\circ}, 6$ reflections 


$$
4 \text { 結棓論 }
$$

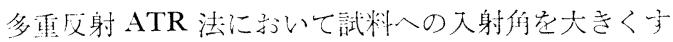
るたやの高屈折率媒質の設計，藏作ォよごこれを用いて の高屈折率試料和よび表面処理藏料の検討老行ない，舆 好な結果ぶ得られた。弯なわ台カーボンブラック入りゴ

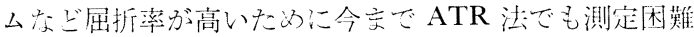
であった試料が入射角 70。で測定可能であり，これらの 化合物の表面劣化なる゙の検时に有用であった。支た同じ

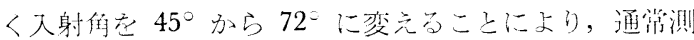

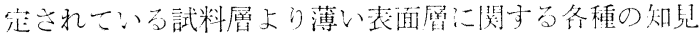
㕕得るこもき可能であった。

$$
(1970 \text { 年 } 7 \text { 月，箱， } 16 \text { 回耍分 })
$$

\section{交献}

1) N. J. Harrick : "Internal Reflection Spectroscopy", p. 30 (1967), (John Wiley \& Sons, New York).
2) 田中誠之，松井とも子，黑田孝二：第 6 回匛用下 ヘクトロメトリー東京峢論会講演要旨集，p. 91 (1970).

$$
\text { st }
$$

Studies on the measurements of polymers by the ATR method utilizing large incidence angles Shigeyuki Tanaka and Tomoko Matsui (Department of Industrial Chemistry, Faculty of Engineering, University of Tokyo, Bunkyo-ku, Tokyo)

KRS-5 crystals were designed and prepared for ATR method utilizing large incidence angles. B using these crystals, samples with high refractive indices or thin coating samples were analyzed successfully. For example, the rubbers with high carbon black contents which were difficult to be measured by usual ATR method because of their high refractivity were possible to be measured by applying the incidence angle $70^{\circ}$. In the same way, changing the incidence angle from $45^{\circ}$ to 72 , several informations were obtained about thinner surface layers than those having been measured by usual ATR method.

(Received Feb. 15, 1971)

\title{
スチルバゾによるジルコニウムの吸光光度定量
}

\author{
小澤 敏 㚘*
}

(1971 年 2 月 22 日受理)

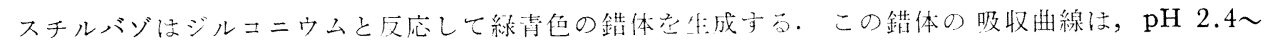
5.0 で $585 \mathrm{~m} \mu$ に等吸收点老与える.こ机を利用して $\mathrm{pH} 3.0$ で吸光光度寉量法について検討した紸 果，0〜1.2 $\mu \mathrm{g} / \mathrm{m} l$ のジルコニウムが定量できた。モル吸光係数は $5.6_{5} \times 10^{4}$ であり, $\log \left(I_{0} / I\right)=0.001$ の感度は $1.6 \times 10^{-3} \mu \mathrm{g} / \mathrm{cm}^{2}$ で市った。

妨害元素はベリリウム (II)，インジウム (III)，ハフニウム (IV)，マンガン (II)，モリブデン (VI), チタン $(\mathrm{IV})$ ，トリウム $(\mathrm{IV})$ ，タングステン $(\mathrm{VI})$ およごバナジウム $(\mathrm{IV}, \mathrm{V})$ などである。またりン酸， シニウ酸，クエン酸および EDTA などが微量でも妨審する。

マンガンおよび微量のチタンはスルホサリチル酸でマスキングできる。きリブデンはチオグリコ、 一ル酸, タングステンはチオシアン酸カリウムとアスコルビン酸とで, 示れぞれ妨害をマスキングでき

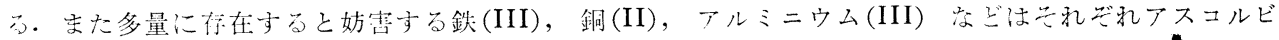
ン酸，チオ尿素，スルホサリチル酸でマスキングできる・

\section{1 緒咅}

ジルコニウム (IV) の吸光光度定量法については，こ

* 東京都立工栄技術センター：東京都北区稻付出井顛 町
れ实で多くの有機試莧が検討されている1)。在のなか で特:アルセナゾ III ${ }^{2}$ )3) は高感度の試薬として一般に 用いられている。

スチルバゾとジルコニウムの反念については Babko

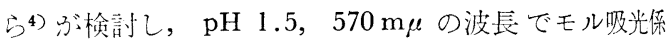

